Author: Joanne Brindley MA, FHEA, PgCLTHE, RDH, RDT

Senior DCP Teaching Fellow, University of Portsmouth Dental Academy

Aim: The focus of this review was to identify the role of reflection in continuing dental education. By understanding the expectations that our statutory regulative authority has of their registrants there is an opportunity to help to shape the Continued Professional Development activities undertaken by current registrants in the future.

Objective: Conduct a review of General Dental Council Fitness to Practise cases which were given conditions (restrictions) between February 2012 and November 2015, identifying relevant emergent outcomes in relation the Fitness to Practice (FTP) process.

Design: A Framework Approach (FA) was used to interrogate the qualitative data generated from GDC cases, the data were reviewed by a secondary person to ensure inter-rater reliability. Ethical approval was not sought for this research project as the GDC cases are published and available for open access via the internet. However, this does not negate the need for consideration of those GDC registrants who have been reviewed by the Fitness to Practise process. Indeed, information regarding their identities was removed during data collection, as individual identification as part of this research project may have impacted on these individuals (bearing in mind the principle of non-maleficence; do no harm) and disclosure of personal information would not have contributed to the findings of this review. Although FTP cases are in the public domain, the information is still sensitive to those registrants; therefore it was not possible to review those cases which were not available for public view. To ensure that individual identification of registrants did not occur for the available to view cases $(n=56)$, each case file was individually downloaded from the GDC website and immediately given an individual numerical identifier prior to the frame work analysis. For the purpose of this research only the data from the FTP cases which resulted in 'conditions' were subject to review, as these were cases where it was felt that the registrants were able to remedy their personal professional practices.

\title{
Introduction
}

Despite the foundations of reflective practice being established as far back as $1938^{1}$ dentistry is still playing catch up. Historically dental education was solely focussed on the undertaking of a practical procedures and techniques ${ }^{2}$, with little time devoted to the need to develop the underpinning cognitive and psychosocial skills which are required to meet the complex demands of modern dentistry. Reflection is now regarded as an important component of dental undergraduate education and post-registration practice ${ }^{3}$. Although, on the surface, reflection sounds like a simple and straightforward undertaking, in reality it is a complex midfield that requires skilful facilitation to ensure that the act of carrying out reflection contributes to learning in a meaningful way at any point of a professional's career.

Reflection has been extolled as a virtue by the various stakeholders relating to dentistry. However, there is a tension; professional reflection is not about paying lip service to a governing body. In order for reflection to become a truly effective activity there is a need for a richer, deeper exploration of the factors that influence the complexities of one's own personal, deep rooted, views and values to occur. Dental education providers now have a moral responsibility to create meaningful opportunities and situations for effective reflective skills development, during undergraduate programmes. This will 
ultimately ensure that the future safe beginner is endowed with the qualities that will enable them to face the challenge of viewing their personal actions and interactions with others in a positive and meaningful way.

The focus of this review was to establish the role of reflection in continuing dental education. The terms reflection, reflective practice and professional reflective practice are littered throughout the literature in nursing, social work, education and in the professions allied to medicine and there is a now a need to define the reflective qualities and processes that should underpin dental education, in both pre and post registration arenas. By understanding the expectations that our statutory regulative authority has of their registrants there is an opportunity to help to shape the Continued Professional Development activities undertaken by current registrants in the future.

\section{Data analysis and discussion}

Borton' $s^{4}$ three stage framework for reflection was utilised for the initial stages of the Framework Analysis; What? Was used to identify the problem, So what? Was used to review the remedial steps taken and the Now what? Aspect reviewed the conditions that the GDC had placed on the registrants, in relation to their future practice.

\section{What? (Awareness of the problem)}

This facet of the FA centred predominately around two main areas; professionalism and insight.

Key phrases were used in several of the cases 'You must recognise that your qualification for registration was the first stage in your professional education' (Cases 3, 15, 20, 42, 48, 51, 53, 55, 56), which is in direct alignment with the GDC's overarching outcomes in relation to education and training 'Recognise the importance of lifelong learning and apply it to practice's. The expectation for continual development was also published in the report Maintaining Quality and Impact of CPD in Dentistry which clearly states no one ever stops learning identifying 'As the practice of dentistry continues to evolve and develop, new techniques and technologies emerge and as such: patient and public expectations of dental professionals change; ways of working and communicating with colleagues and patients also change, along with the values of society' ${ }^{6}$.

Professionalism encompassed not only practical skill but also attitudes, behaviours and developmental skills a registrant should be able to demonstrate. Thus heralding the move from the older style, practically focused aspects of dental education. Indeed, in several cases registrants were identified as being unable to demonstrate that they had continuously reviewed 'their knowledge, skills and professional performance. Reflect on them, and identify your limits as well as your strengths' (C3, $\mathrm{C} 5, \mathrm{C} 7, \mathrm{C} 15, \mathrm{C} 17, \mathrm{C} 42, \mathrm{C} 44, \mathrm{C} 47, \mathrm{C} 48, \mathrm{C} 51, \mathrm{C} 55$ \& C5) and so meeting GDC standard 7.3. ${ }^{7}$. It should be remembered that it is quite possible that some of the registrants that have been taken to FTP may have never experienced any formal education in relation to their reflective skill development, either because they became a registrant prior to the inclusion of reflection into the dental undergraduate curriculum or because they have registered in another country who's scope, practice and expectations of registrants may differ. If we are serious in accepting that reflection should regarded as a core facet of individual professional competence, then we need to know far more about its structure, substance, nature ${ }^{8}$ and expectations of our statutory bodies surrounding its use. 
C54 further reinforced the need for the development of professional and practical aspects of their practice, with the FTP panel stating that 'issues identified in this case may theoretically be remediable but are more difficult to remedy that clinical deficiencies', demonstrating that it is not enough to be clinically competent at undertaking a clinical activity but there is also a prerequisite to possess softer, more emotionally intelligent skills, such as the core values outlined in the NHS Constitution ${ }^{9}$; respect and dignity, compassion and everyone counts, which are all applicable in this case. The lack of forward planning was also evident in C2 'Much of your previous CPD was not directly targeted....you have not fully realised the impact that your failings could have on patients and colleagues'.

In other cases it was clear that there had been no attempt to undertake any professional development activities 'Failed to maintain your professional knowledge and competence' (C20) and 'These shortcomings relate to, and arise out of, deep-rooted and attitudinal deviations from safe and acceptable standards of practice' (C24)

The impact of a registrants actions on the public and professional colleagues was also explored, for example in C51 'you accepted in evidence that your response has been reactive opposed to proactive' which identified the need for professional accountability and forward planning to occur in order to protect patients. Alongside the need to step back and review personal actions 'you lacked insight into your behaviour, how seriously it might have impacted on the patient and how you would react differently in the future' (C54).

C55 clearly showed the impact of DeBono' ${ }^{10}$ 'intelligence trap' stating that 'You have acknowledged that you were over-confident and did not realise that your practice was of the standard it should have been.' This shows that the registrant had been willing to take the time to reflect on and take accountability for their actions that they would have avoided the shortcomings that facilitated their poor practice.

\section{So what? (Remedial steps taken)}

The theme from this aspect of the cases was development. In some of the cases registrants had clearly attempted to identify and address their shortcomings, however, the comments from the FTP panel were clear 'It considers that the action plan and personal development plan, which merely sets out a list of your GDC continuing professional development (CPD) requirements, do not demonstrate that you are committed to addressing these shortcomings in a meaningful and substantial way' (C24) and 'Some of the evidence you presented involves reading journals but there are no reflective logs on the outcome of your learning. You also demonstrated limited insight into how your learning would be embedded into your practice. Whilst you have done some remediation and demonstrated some insight and reflection into your failings, further training is required to bring your practice to the current standard expected' (C41). In C45 the registrant has taken some responsibility for their actions 'You have revealed a degree of insight by admitting to many of the shortcomings which this Committee has found proved'. There were also positive aspects that had been considered by the FTP, as in C44 'The bundle includes your personal development plan (PDP), certificates and particulars of your continuing professional development (CPD), notes of your reflective learning, commentaries on texts and journals that you have read, a significant event analysis, record-keeping and radiographic audits and supporting testimonials.' However, despite these more positive aspects, a note of caution was aired 'you have not shown any evidence of any direct mentorship which may have helped you to remediate this area of your work in full' which helps to underpin that although clinical practice can be in essence 
an isolating experience, there appears to be an expectation that registrants are able to integrate themselves into a more broader 'community of Practice'11. If there is an expectation that mentorship or peer review should be incorporated into CPD activities, this should be formally relayed to registrants, especially with the advent of Enhanced CPD on the horizon.

\section{Now what? (Conditions placed on registrants)}

In all of the cases conditions were attached to the registrants practice. Fifteen cases were directly asked to produce reflective logs and a further thirty-eight registrants were requested to submit Personal Development Plans for regular review, via submission to the Postgraduate Dental Dean (in the majority of cases) or direct submission to the GDC. Either way, there is clear expectation that an aspect of reflection must be included (C54) 'Personal Development Plan must include reflection on the impact of his academic learning on his day to day clinical practice.' and C21 'enable you to properly reflect and develop an improved level of insight into your failings'. In terms of content, the importance of reflection in the development of learning needs is widely recognised. As early as 1999 Cantillon and Jones ${ }^{12}$ conducted a systematic review which sought to capture what makes a personal development activity more effective than others (in terms of influencing clinical practice). In their summary they identified that prior personal reflection on learning needs was found to be an important factor in directing the uptake of effective educational activity. An aspect of educational development that undergraduate dental training establishments must be certain to address, if they are to avoid the pitfalls of inadequately preparing registrants for future practice.

For some cases, there had been a direct attempt to redress any problems by the registrant, but even though aspects of reflection had been included, it was clear that 'lip service' was not enough 'The Committee determined that in the light of the useful but limited evidence that you have provided, it is not satisfied at this stage that you have fully developed an appropriate level of insight and reflection' (C55) and again in C56 'Your PDP is limited to one page and is deficient in content and reflection.' and in $\mathrm{C} 40$ 'must produce a document which demonstrates self-reflection upon the failings'. Bolton ${ }^{13}$ describes the useful role that reflection has in allowing time to reflect upon emotional situations and helping to explore and discover ethical values in practice. Registrants need to be aware that people from cultures and religions different from our own, may well have very different and equally strong needs that we must be mindful of in our daily practice.

Meetings on a regular basis with the Postgraduate Dental Dean (or similar) were commonplace, varying from weekly 'The registrant's work must be reviewed at least once weekly by the supervisor via one to one meetings and case-based discussion.' (C32) to 'maintain a log detailing every case. He must provide a copy of the log to his indirect supervisor, on a monthly basis' (C25) and on other occasions this information must be also be shared with the FTP, as in C15 'must allow her workplace supervisor to provide reports to the GDC at intervals of not more than 3 months and the GDC will make these reports available to any Postgraduate Dean/Director and any other person involved in her retraining and supervision.'. The role of mentorship on a more formal basis is can be incredibly supportive, as Bolton ${ }^{13}$ describes 'it is like standing in front of the mirror with someone else.........Mentors ask questions one does not, or cannot, ask oneself'. Indeed mentors provide a helping-to-learn relationship ${ }^{13}$ that encompasses; role model, enabler, teacher, encourager, counsellor, befriender, facilitator, coach, confidante and supporter.

Table 1 The initial themes and overarching concept derived from the Framework Analysis process 


\section{Limitations}

The review of the GDC cases had both positives and negatives. Positively the data was readily available online (with the exception of cases which were subject to health reasons) and the findings of the FTP panel were clearly articulated. The most negative aspect was due to the fact that not all of the cases could be reviewed. The FTP panel also varies in their membership so the decisions made may well be subject to some comparability issues, but invariably there will been some cross pollination of FTP panel members.

In order for research to be valid it must be reliable ${ }^{14}$ and if the researcher can demonstrate validity it is in turn ensuring the reliability. The validity in this instance is underpinned by the source of the data (from the GDC) and in the framework analysis, which enables a clear audit trail of how decisions have been reached, which in turn demonstrates the trustworthiness of this aspect of the research process.

\section{Conclusion}

The overarching theme from this research is 'insight'. Insight is defined by the Oxford English Dictionary ${ }^{15}$ as 'the capacity to gain an accurate and deep understanding of someone or something'. The term 'accurate' is derived from the Latin word 'accuratus' (done with care) and the noun 'understanding' can be defined as the power of abstract thought which relates to an individual's perception or judgement of a situation ${ }^{15}$. This epitomises the qualities that are required to become a truly reflective professional practitioner, just like the fire triangle (oxygen, heat and fuel) which are required in order for a fire to burn, so are these prerequisites required for professional reflection to occur; for without perception and judgement of a situation, insight into our actions both during and after the event (in and on action) and our own innate personal duty of care, we are unable to gain true understanding of the impact of our actions on our patients, fellow professionals and the world around us, at any point of our professional lifelong learning journey.

\section{Figure 1 Prerequisites for dental reflection}

\section{References}

${ }^{1}$ Dewey, J. (1938) Logic-The theory of Inquiry. New York: Henry Holt \& Company

${ }^{2}$ Sweet, J., Wilson, J., \& Pugsley L. Educational innovations for dentistry. British Dental Journal, 2009, 206, 29-34

${ }^{3}$ Tricio, J., Wolford, M., \& Escudier, M. Dental students' reflective habits: is there a relation with their academic achievements? European Journal of Dental Education, 2014, 19(2), 113-121

${ }^{4}$ Borton, T. Reach, Touch and Teach. London:Hutchinson, 1970 
${ }^{5}$ General Dental Council (2013). Continuing Professional Development for dental professionals. Retrieved from http://www.gdc-uk.org/Dentalprofessionals/CPD/Pages/cpdrequirements.aspx ${ }^{6}$ General Dental Council. Maintaining Quality and Impact of CPD in Dentistry: CPD review. London: GDC, 2012

${ }^{7}$ General Dental Council. 2013. Standards for the Dental Team Online information available at https://www.gdcuk.org/Newsandpublications/Publications/Standards\%20for\%20the\%Dental\%20Team.pdf (accessed December 2015).

${ }^{8}$ Ixer. There's no such things as reflection. British Journal of Social Work, 29, 513-527

${ }^{9}$ The NHS Constitution online information available at https://www.gov.uk/government/publications/the-nhs-constitution-for-england/the-nhsconstitution-for-england (accessed October 2015).

${ }^{10}$ De Bono, E. I am right, you are wrong: From this to the new renaissance: From Rock to Water Logic. London: Penguin books Ltd, 1990

${ }^{11}$ Wenger, E. (1998). Communities of Practice: Learning as a social system. Online information available at http://www.open.ac.uk/ldc08/sites/www.open.ac.uk.Idc08/files/learning.pdf (accessed April 2015)

${ }^{12}$ Cantillon, P. and Jones, R. Does continuing medical education in general practice make a difference? British Medical Journal 1999, 318, 1276-1279

${ }^{13}$ Bolton, G. Reflective Practice: Writing and professional development (4th Ed). London: Sage, 2014 ${ }^{14}$ Lincon, Y.S., \& Guba, E.G. But is it rigorous? Trustworthiness and authenticity in naturalistic evaluation. New Directions for Program Evaluation, 1986, 30, 73-84

${ }^{15}$ The Oxford English Dictionary Online information at http://oxforddictionaries.com (accessed December 2015) 